\title{
Dissipation of Fenitrothion Residues in Some Fruits and Vegetables Using High-Performance Liquid Chromatography Method
}

\author{
Saleh Omar S. Bahaffi ${ }^{*}$, Faten M. Zainy and Abdul Ghni Hamza \\ Department of Chemistry, Faculty of Science, \\ King Abdulaziz University, Jeddah, Saudi Arabia
}

\begin{abstract}
AвSTRACT. High performance liquid chromatographic method was described for the determination of the dissipation of fenitrothion residues in some fruits and vegetables. Crops were sprayed with very dilute solution of fenitrothion, and collected daily one day after spraying for 7 to 13 days, and then extracted with acetonitrile and partitioning in normal hexane. Solid phase florisil cartridges were used for clean up. The analysis was carried out by reversed-phase high performance liquid chromatography (HPLC) with methanol-water (90:10) as a mobile phase. Detection limit is $0.01 \mathrm{mg} / \mathrm{kg}$. The percentage of losses are $89.55,85.71,76.01,93.39,98.75$, and 99.24 for rocket, parsley, lettuce, fig, grape and guava, respectively.
\end{abstract}

\section{Introduction}

Organophosphorus pesticide came into general use in early 1960s. The growth in use of these compounds as a result of the resistance of insects toward chlorinated pesticides. Fenitrothion (o,o-dimethyl 4-nitro-3-methyl-phenylphosphonothionate) $\left[\mathrm{C}_{9} \mathrm{H}_{12} \mathrm{NO}_{5} \mathrm{PS}\right]$ is an organophosphorus insecticide. It is used almost worldwide for such crops as rice, fruits, vegetables, cotton, cereals and soybeans. It is also used in public health, principally as residual spray in houses for control of mosquitoes. It has low toxicity to mammals ${ }^{[1]}$. The toxicity is much lower than many similar insecticides. $\mathrm{LD}_{50}$ the amount or concentration of a toxicant required to kill $50 \%$ of the test animal population under a standard set of conditions is $800 \mathrm{mg} / \mathrm{kg}^{[2]}$. Maximum Residue Limits (MRL's) permitted by Food Agriculture Organization (FAO) is $0.5 \mathrm{ppm}^{[3]}$. Gas chromatography (GC) is the basic technique for analysis of several multiresidue pesticides in 
plants $^{[4-6]}$ (HPLC) is the most important alternative to GC for pesticide residue analysis $^{[7-10]}$. Liquid-liquid partitioning and adsorption chromatography have been traditionally applied forclean-up ${ }^{[11,12]}$. Head space solid-phase microextraction was used in strawberries and cherries ${ }^{[13]}$. Fast supercritical fluid extraction and high-resolution gas chromatography with electron-capture and flame photometric detection was used for multiresidue screening of organochlorine and organophosphorus pesticides in Brazil's medicinal plants ${ }^{[14]}$. Supercritical fluid extraction was also used for removal of organophosphate pesticides from waste water by supercritical carbon dioxide extraction ${ }^{[15]}$. This paper describes the dissipation of fenitrothionin six crops, which are rocket, parsley, lettuce, fig, grape and guava over a period of time. Florisil cartridges were used for clean-up prior to analysis by High-Performance Liquid Chromatography (HPLC).

\section{Experimental}

The study was carried out at the Agricultural Research Center, King Abdulaziz University, Faculty of Meteorology, Environment, and Arid Land Agriculture, at Hada Alsham region. The study included spraying the pesticide on three types of fruits (fig, grape, and guava) and three types of vegetables (lettuce, rocket, and parsley).

\section{Pesticide Spraying}

Pure or undiluted pesticides are highly toxic to both animals and plants, so they must be diluted before spraying. According to a procedure used in the farm where $4.5 \mathrm{~g}$ of fenitrothion dissolved in 5 liters of water to form liquid emulsion, then placed in the sprayer (Honda Electronic Ignition GX 270). Five basins of vegetables and three trees of fruits were sprayed with the emulsion (one of each remains without spray as blank).

\section{Crops Sampling}

Twenty-four hours after spraying, the first batch was collected from each plant and transferred to the laboratory, this process was followed regularly to the end of the period (7-13 days).

\section{Extraction and Clean-up Procedures}

The sample extraction was based on the method described by Sastry and Vijaya $^{[10]}$. A $25 \mathrm{~g}$ sample of each of lettuce, rocket, parsley, fig, grape, and guava was homogenised with acetonitrile $(50 \mathrm{ml})$ in a blender. The extract was filtered through a Buchner funnel by suction and washed twice with $10 \mathrm{ml}$ of acetonitrile. The combined filtrate was used for partitioning in a separatory funnel 
with $50 \mathrm{ml} \mathrm{n}$-hexane with strong shaking for 5 minutes. Then $50 \mathrm{ml}$ deionized water and $5 \mathrm{ml}$ saturated sodium chloride solution were added and the contents were shaken slowly in a horizontal direction for one minute. The lower aqueous layer was discarded and the upper organic layer containing the pesticides was collected and washed twice with $25 \mathrm{ml}$ deionized water. The extract was dried using a minimum amount of anhydrous sodium sulphate, and filtered. Then, the filtrate was concentrated to $5 \mathrm{ml}$ with rotary evaporator under vacuum at $40^{\circ} \mathrm{C}$. The organic extracts were cleaned up prior to HPLC analysis using florisil cartridges, which were rinsed with $20 \mathrm{ml}$ of $\mathrm{n}$-hexane for conditioning. The sample was applied to the cartridge by syringe. Finally the analyte was eluted from the sorbent using $10 \mathrm{ml}$ of a mixture of $\mathrm{n}$-hexane and acetone in the ratio of 80:20.

\section{Reagent and Standard}

HPLC-grade acetonitrile, methanol, n-hexane, acetone and analytical grade sodiun sulfate and sodium chloride were obtained from BDH, (England). Water purified using Milli-Q Plus Sytem (Millipore, Bedford, MA, USA) was used for solution preparation. Fenitrothion pesticide standard was obtained from Allied Signal, (Riedle-deHaen, Germany).

\section{HPLC Instrumentation}

A Beckman HPLC system consisting of 114 multisolvent delivery system, programmable 165 variable wavelength detector, 7725i Rheodyne injector fitted with $20 \mu \mathrm{l}$-sample loop. The column was Ultraspere C-18, $5 \mu \mathrm{m}, 250 \times 4.6 \mathrm{~mm}$, Beckman. The column effluent was monitored at $254 \mathrm{~nm}$ and 0.01 absorbency unit full scale. The mobile phase was composed of methanol-water (90:10) and the flow-rate was $1.0 \mathrm{ml} / \mathrm{minute}$. The solvent used was of HPLC grade and filtered through 0.45 and $0.5 \mu \mathrm{m}$ Millpore filter paper and degassed with Ultrasonic (Brasonic $2210 \mathrm{R}-\mathrm{DTH}$ ) before using.

\section{Results and Discussion}

The dissipation of fenitrothion from the six plants is shown in Table 1. The initial concentration in the first day after spraying in $\mathrm{ppm}$ for fenitrothion on rocket, parsley, lettuce, fig, grape and guava are 2.017, 3.397, 0.4581, 0.7575, 2.303 and 19.40 , respectively. Then decrease gradually reaching $0.2108 \mathrm{ppm}$ after 12 days in rocket the percentage of losses being $89.55 \%$. For parsley the final concentration is 0.4854 to reach $85.71 \%$ after 13 days. In lettuce the period of experiment is only 7 days that gives $76.01 \%$ of residue losses. On the other hand for the fruits the initial concentration in figs is $0.7575 \mathrm{ppm}$ and the final concentration after 12 days is $0.0500 \mathrm{ppm}$ and percentage losses is $93.39 \%$. For 
grape the initial concentration is 2.3030 and the final concentration is 0.0287 ppm after 11 days and the pecentage losses is 98.75 . Finally the guava has the highest initial concentration in the first day $19.40 \mathrm{ppm}$, while in the final day the concentration was $0.1474 \mathrm{ppm}$. Figure 1 shows the dissipation of fenitrothion in the six crops used in this study.

TABLE 1. The dissipation of fenitrothion from the six plants in ppm.

\begin{tabular}{|c|c|c|c|c|c|c|}
\hline Day & Rocket & Parsley & Lettuce & Fig & Grape & Guava \\
\hline 1 & 2.017 & 3.397 & 0.4581 & 0.7575 & 2.303 & 19.40 \\
2 & 1.635 & 3.231 & 0.4154 & 0.5666 & 0.8589 & 3.145 \\
3 & 1.041 & 2.864 & 0.3995 & 0.4936 & 0.8209 & 2.226 \\
4 & 1.019 & 2.233 & 0.2190 & 0.4687 & 0.6582 & 0.6754 \\
5 & 0.849 & 1.926 & 0.1767 & 0.4414 & 0.6569 & 0.6782 \\
6 & 0.844 & 1.319 & 0.1586 & 0.3539 & 0.4425 & 0.4140 \\
7 & 0.6880 & 1.270 & 0.1099 & 0.3375 & 0.4184 & 0.0372 \\
8 & 0.6875 & 1.254 & - & 0.3066 & 0.3916 & 0.3446 \\
9 & 0.5975 & 1.154 & - & 0.2505 & 0.3265 & 0.2642 \\
10 & 0.5281 & 0.794 & - & 0.2218 & 0.2590 & 0.1638 \\
11 & 0.2787 & 0.788 & - & 0.0952 & 0.0287 & 0.1602 \\
12 & 0.2108 & 0.7444 & - & 0.0500 & - & 0.1474 \\
13 & - & 0.4854 & - & - & - & - \\
$\%$ of loss & $89.55 \%$ & $85.71 \%$ & $76.01 \%$ & $93.39 \%$ & $98.75 \%$ & $99.24 \%$ \\
\hline
\end{tabular}

Dissipation pattern of Fenitrothion from six plants

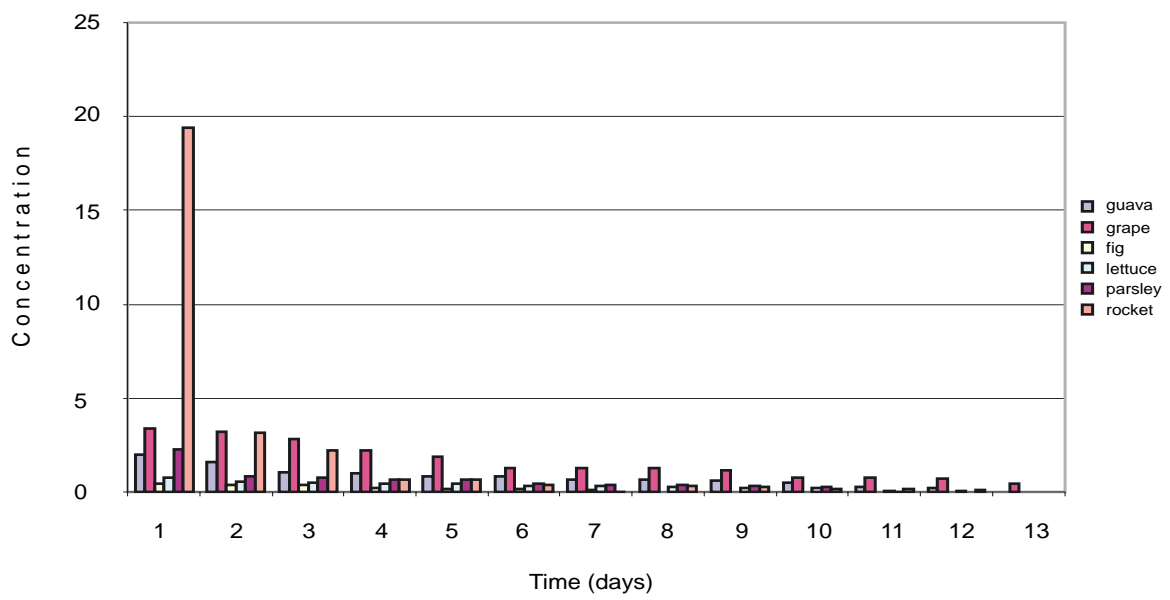

FIG. 1. Dissipation of fenitrothion residues in the six crops used in this study. 
Solid-phase extraction reduced the analysis time and solvent consumption compared with traditional methods such as liquid-liquid extraction. The present data indicate that solid-phase extraction using florisil cartridges is capable of effecting rapid clean-up of fenitrothion from hexane extracts of vegetables and fruits. The peak areas of the monitoring fenitrothion on the chromatograms were measured, and the concentration of pesticide residue was determined from the calibration curve.

\section{Conclusion}

Periodic analysis of the treated vegetables and fruits over 7-13 days showed progressive dissipation especially in the first days. Sep-Pack solid-phase florisil cartridges were used for clean-up. Reversed-phase high performance liquid chromatography at wavelengh of $254 \mathrm{~nm}$ was used for the determination. The detection limit is $0.01 \mathrm{ppm}$. The period of study was suitable for dissipation of pesticide from crops to reach less than maximum residue limit permitted by Food Agriculture Organization (FAO) and World Health Organization(WHO $)^{[16]}$.

\section{References}

[1] Sastry, C.S.P. and Vijaya, D., J. Fd. Sci. Technol., 23: 336-338 (1986).

[2] Balinova, A.J., Chromatogr. A, 823: 11 (1998).

[3] Tuinstra, L.G.M.T., Povel, A.H. and Roos, A.H., J. Chromatogr. 552: 259 (1991).

[4] Gelsomino, A., Petrovi ova., Tiburtini, S., Magnani, E. and Felici, M., J. Chromatography A, 782: 105-122 (1997).

[5] Bovanovab, L. and Brandsteterova, E.J., Chromatogr. A, 880, 1-2: 149-168 (2000).

[6] Diserens, H. and Henzelin, M.J., Chromatogr. A, 833, 1: 13-18 (1999).

[7] Ohlin, B., Var Foda, 86, 2: 111-124 (1986).

[8] Ohlin, B. and Flygh, E., Var Foda, 86, 1: 56-63 (1983).

[9] Funch, F.H ., J.F. Bergmann Verlag, 173: 95-98 (1981).

[10] Tsipi, D., Triantafyllou, M. and Hiskia. A., J. Analyst, 124: 473-475 (1999).

[11] Lehotay, S.J. and Eller, K.I., J. Assoc. Off. Anal. Chem., 78: 831 (1995).

[12] Ambrus, A., Lantos, J., Visi, B., Csatlos, I. and Sarvari, L., J. Assoc. Off. Anal. Chem., 64: 733 (1981).

[13] Lambropoulou, D.A. and Albanis, T.A., J. Chromatogr. A, 993, 1-2: 197-203 (2003).

[14] Zuin, V.G., Yariwake, J.H. and Bicchi, C., J. Chromatogr. A, 985, 1-2: 159-166 (2003).

[15] Yu, J.J., Water Research, 36, 4,1095-1101 (2002).

[16] Muud, S.Z. and Hasan, N.J., Sci. Ind. Res., 35, 12:499-504 (1992). 


\title{
تبدد بقايا الفينترون في بعض الفو اكه والخضر اوات باستخدام

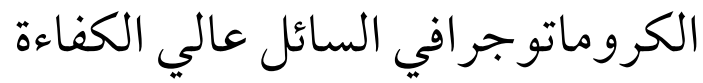

\author{
صالح عمر سعيد باحفي ، و فاتن محمد زيني ، و عبد الغني حمزه

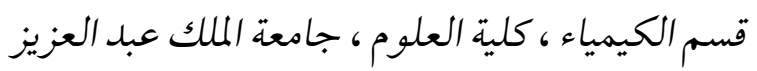

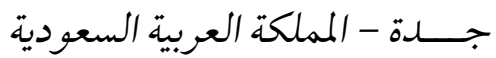

المستخلص. تم في هذ البحث وصف طريقة لتقدير تبدد بقايا مبيد

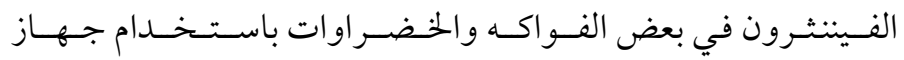

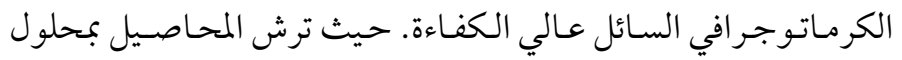

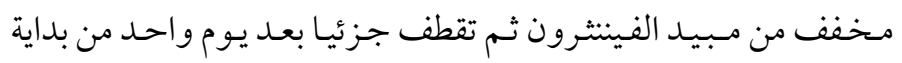

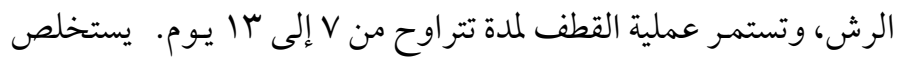

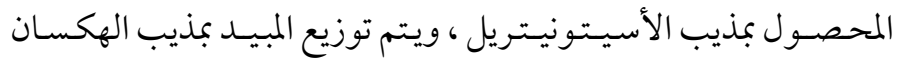

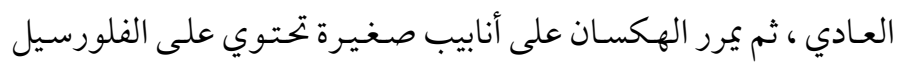

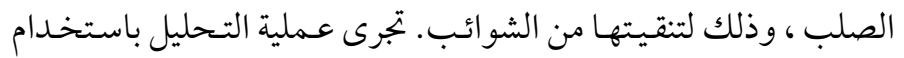

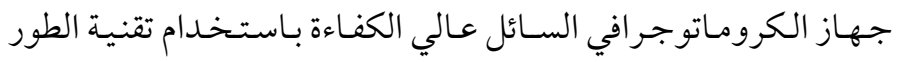

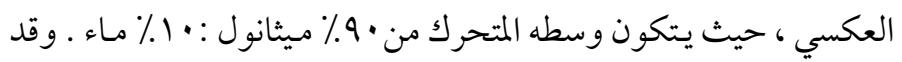

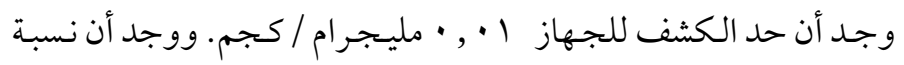

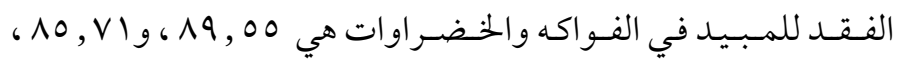

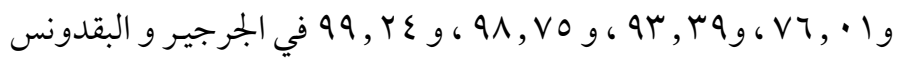

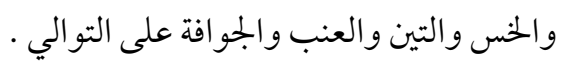

